\title{
An Attempt at Making Urban Design Principles Explicit
}

\author{
IRIS ARAVOT \\ Technion/Israel Institute of Technology \\ Israel
}

\begin{abstract}
Since its rise as an autonomous field in the seventies, Urban Design has been a conglomerate of diverse concepts and value outlooks. The present approach, which is an a posteriori propositional expression of applications in actual practice and education, presents both theory and method by means of ten points. The approach is basically generated by formal considerations, thus originating in and focussing on aspects which cannot be expressed through theory and methods of other disciplines. It starts with systematic, conventional and objectiv studies which are then connected to a system of manipulations - the rules of game - which emphasize interpretation and are clarified by narrative and formal metaphors.

The 'rules of game' set a framework of no a priori preferred contents, which is then applied according to local characteristics, needs and potentials. This conceptual interpretative framework imposes a structural, consistent and hierarchical system on the factual data, so as to assure the realization of two apparently opposed values: (1) unity and phenomenological qualities and (2) free development and unfolding of the design that .The propositional expression of the approach aims at its exposure to explicit evaluation and criticism.
\end{abstract}

\section{INTRODUCTION}

Since the seventies, when urban design was acknowledged as the required practical as well as theoretical bridge between the then dissociated spheres of architecture and town planning, its subject matters, its means and its objectives have been given a variety of interpretations. (e.g. Gosling and Maitland, 1984). Some of these interpretations are complementary, (e.g. Cullen, 1971, and Bacon, 1967), many are simply unrelated (e.g. Koolhaas, 1978 and Appleyard, 1964), and some - even opposed (e.g. Lynch, 1981 and Rowe, 1978, or Krier, 1979, and Venturi, 1972).

The multitude of approaches arises not only from different responses to different problems and situations, but first and foremost from a variety of basic value outlooks and premises. Since value outlooks and premises can only be exposed but not refuted, no decision among the various approaches seems possible or desirable, except on the basis of additional value outlooks and premises, and so on, until the unsolved problem of ultimate values justification is reached.(Aravot, 1991a)Still, on the condition of rational and explicit discussion, there are possibilities for syntheses. Such is the present approach.

\section{THE 'RULES OF GAME'}

Any actual process of urban design, is not simply linear, but contains parallel, overlapping and cyclical sections. For the sake of discussion, however, the 'rules of game' will be presented in a linear, sequential and clearly differentiated manner.

\section{Artistic Intentionality}

Acts of urban design are of artistic intentionalities. Like all arts, urban design originates in formal interpretations of phenomena. It does not provide for imitation or "translation" of reality, but for its rediscovery and intensification towards the endless formal possibilities in potential.(after discernments of E.Cassirer (Cassirer, 1970). As such, our first rule defines activation of the artistic capacity as the required atmosphere or disposition for actual urban design intervention, and implies the value of forms for the scale of urbanity.

\section{Ad-Hoc and Ad-Interim Ideal Image}

The objective of a specific activity of urban design is to create a guiding value: an ideal image as the ad-hoc and adinterim generator of a town or its part. The ideal image establishes an 'individual law' for a place, a time and a designer. The image as such is not realizable because it is highly indefinite: it is more of a symbol than a plan or a sign, a guiding value much more than a model. The ideal image provides for generators (narrative and form) which require further interpretation and elaboration. Still, and in much opposition to Renaissance Ideal Cities, the present ideal image does not claim an absolute value position,but an ad hoc and ad interim status. It calls for dynamic re-interpretations and redefinitions along time. (cf., the C.I.A.M. 
position (Le Corbusier, 1973), which was deontological and absolutist).

\section{Reading of Forms}

The act of urban design originates in reading of forms within the integrative contextual map. This process yields the urban generators. All components of a specific urban subject matter that have among their attributes a location or a direction factor, may be clustered and simultaneously represented on a two or three dimensional map. This integrative, situational map, which contains all the "is" and "ought" data, as far as practical constrains permit, is the contextual map of a place, and the one which secures the link between the art of urban design and all other facets of reality. This is the background for the "reading of forms", a term is borrowed from E. H. Gombrich's "Meditations on a Hobby Horse", implying that people tend to interpret according to their interest. Not unlike the cave man in Altamirah and Alasco,the urban designer too reads urban structures within the contextual map. Emphases, completions, extractions, additions, frequently even minor ones, suffice to "reveal" the town's implicit nature, in a mode not very different from a Louis Kahn answer to a "What does the building want to be ?" question.

\section{Hierarchical Activation}

Urban design concerns the manipulation of symbols in a minimum ofthree phases: (a) the preliminary : reading of forms, (b) the central: definition of a formal ideal through urban generators, and (c) the critical: elaboration and articulation of generators, which is to demonstrate that the generators are not empty symbolizers, but that they can be exchanged for the symbolize. The three phases are the minimal representation of a continual process, which leads from urban design to architecture, and from the abstracted and the generalized to the concrete and the specific. The larger the initial scale - the longer the process. At any phase the town is regarded as a puzzle of "urban matter" (urban tissue, urban elements etc.), metaphorically defined, and alluding to a synthesis of approaches as remote as Lynch, (Lynch, 1964), Rossi (Rossi, 1982) and Alexander (Alexander et al.,1977). Starting with phase (b),(urban generators) the puzzle has a continuous extension with no empty gaps.

\section{Potentiality and Actualization.}

Every level of representation contains the potentiality to be actualized in the next level,i.e. something implicitly symbolized that must become explicit. The implicit is compound of elements and relations. Becoming explicit concerns the materialization of relations, and therefore the increase in number of both elements and relations. Passing over from the potential to the more actual demands interpretation. Unexploited potentiality is a deficiency, which, once acknowledged, leads either to the completion of the required interpretation or to a further acknowledgment that the given symbol is barren and therefore has to be exchanged.

\section{The Geometry of Generators.}

The generators create a clear, legible set of lines, dots and planes. (cf. Lynch, 1964). No preference for symmetry, orthogonal geometry, repetition or any other form of regularity is presupposed. The only geometrical conditions are that planes intercut by borders, i.e. lines, that every line is initiated and ended by a dot, that a break of direction is marked by a dot and that no dot is disconnected. The affinity between form and content entails that any change in the geometry of generators represents a change in content or "urban matter" and vice versa.

\section{Metaphors.}

The need to define urban elements ("tissue", "matter", components, "generators") by metaphors (1), is caused by the restriction, wearing away and poverty of conventional notions in comparison to the wealth of existing and potential urban situations (2), the more so on the background of the above 'individual law' and unique image requirements. A metaphor states attributes of content and form. Alike a notion, is only partially defined, however, unlike a notion it does not hold imagination back, but opens up hermeneutic possibilities. Metaphors tend to draw on almost unlimited sources of origin at preliminary stages of urban design, (e.g. Aravot, 1991b) gradually passing over to professional precedents.

\section{Internal Relations.}

Any two elements (urban or others) are of external relations if the existence of one is indifferent to the existence of the other, i.e. if the elimination or change of the first does not affect the second in any way. Accordingly, any two elements are of internal relations if the very existence of one is influenced by the existence of the other, so that modifications of one element entail corresponding modifications of the other.

The present approach suggests that the relations among urban components are internal, first and foremost so between two adjoining ones. As such, a component (e.g."a") undergoes change as soon as an additional component (e.g."b") comes into existence in its immediate boundaries, and "a" cannot be affected in the same way by its boundaries with " $b$ " and "c", unless these two last components are themselves identical.The intensity of internal relations may exceed adjoining components and reach to further remote ones.

\section{Dialectical Transformation.}

Passing over from one phase of urban design to the successive one concerns interpretation, refinement, actualization an concretion, as well as an increase in number and complexity of elements and relations. We assume that urban matter "a" and urban matter "b" are internally related . In the next phase the relation (<-ab->) is actualized by a third urban matter "c", which in turn has internal relations with "a" (<$a c->)$ and with "b" (<-cb->), and so on. This process points 
at a paradoxical phenomenon: a relation between urban components is accepted as a relation only as long as it is kept at the margins of the field of attention. Once brought into focus it is interpreted and materialized; and vice versa: when attention is focussed on an urban component, the component is fragmented into edges (relations) and central body.

\section{Coherence and Enrichment.}

Despite the increase in number and the multitude of interpretations, the dialectical process of urban design must retain its unity with the initial ideal image, the generators and their metaphorical and formal attributes. Late phases are more complex, fragmentary and concrete than earlier ones. Unity, diversity and wealth of content and form are extensively accepted urban qualities (from Sitte, 1890 to Lynch, 1981). Coherence, however, is hereby proposed as a characteristic required from the process of urban design only. Its value lies in being a precondition for inter-subjective discourse and criticism (which seem to require no justification for themselves). Otherwise it may be abandoned or kicked away like a ladder which brought us up and is needed no more.

\section{SUMMARY}

The approach presented in this essay was termed "a formal game" both because of the emphasis on urban form and because, like a game, it is formal and conventional, and therefore may be substituted by other games, but never reduced to other games. Light was shed on the special contribution of the urban designer as channeled by artistic intentionality, thus redefining the task of urban design as a bridge between architecture and town planning. As this contribution is essentially a three dimensional generating system that renders a town (or its part) meaningful and structured, the basic values discussed are also formal.

Some of the values may be support by scientific research, others - by philosophical positions, and others - by paradig- matic professional approaches. However, since the process in its entirety is a link in a dynamic chain of reinterpretations, its exposing to explicit discourse and criticism may assure continual readjustment and improvement.

\section{ACKNOWLEDGEMENT}

An extended version of this paper has been accepted for publication in the Journal of Architectural and Planning Research.

\section{REFERENCES}

Alexander, Christopher, Ishikawa, Sara and Silverstein Murray (1977); A Pattern Language; Oxford University Press

Appleyard, Donald (1964); The View From The Road; M.I.T. Press

Aravot, Iris (1991a); Architectural Artifacts and their Linear Justification; Journal of Architectural Planning and Research, volume 8 , no. 1, (pp.11-24)

Aravot, Iris (1991b); Observation and Production of Architectural Myths; Proc. P.A.P.E.R. Conference, Auckland, New Zealand, (pp.17-31)

Bacon, Edmund (1967); Design of Cities; The Viking Press

Cassirer, Ernst (1970); An Essay on Man; Bantam Books

Cullen, Gordon (1971); The Concise Townscape; The Architectural Press

Gosling, David and Maitland, Barry (1984); Concepts of Urban Design; Academy Editions / St. Martins Press

Koolhaas, Rem (1978); Delirious New-York; Academy Editions

Krier, Robert (1979); Urban Space; Rizzoli

Le Corbusier, (1973); The Athens Charter; Grossman Publishers Lynch, Kevin (1960); The Image of the City; M.I.T., Harvard University Press

Lynch, Kevin (1981); A Theory of Good City Form; M.I.T. Press

Rossi, Aldo (1982); The Architecture of the City; M.I.T. Press

Rowe, Collin and Koetter, Fred (1978); Collage City; M.I.T. Press

Sitte, Camillo (1965); City Planning According to Artistic Principles; (orig. Stadbaukunst, 1890), trans. G.\& C. Collins; Random House

Venturi, Robert et. al.(1972); Learning From Las Vegas; M.I.T. Press 